\title{
FOLDING OF WOVEN COMPOSITE STRUCTURES
}

\author{
J.C.H. Yee and S. Pellegrino ${ }^{1}$ \\ Department of Engineering, University of Cambridge \\ Trumpington Street, Cambridge CB2 1PZ, UK
}

\begin{abstract}
This paper investigates one-ply and two-ply laminates made from woven T300 carbon fibre and Hexcel 913 and 914 epoxy resins. These laminates are of interest for deployable structure applications. The maximum surface bending strain, measured by means of a large-displacement buckling test, is found to be $2.8 \%$ for one-ply and $1.9 \%$ to $2.2 \%$ for two-ply specimens in the direction of the fibres. In tension the maximum strains in the fibre direction are $0.9 \%$ to $1.0 \%$ and in compression $0.4 \%$ to $1.0 \%$.
\end{abstract}

Keywords: CFRP, deployable structures, tape springs

\section{INTRODUCTION AND BACKGROUND}

Self-deployable carbon fibre reinforced plastic (CFRP) booms with integral self-locking hinges that are made by cutting three parallel slots in a thin-walled tube with circular cross-section are currently being developed. The slots divide the tube into three strips with curved cross-section, which can be flattened transversally and then bent longitudinally to form an elastic hinge such as that shown in Figure 1. The inspiration for this foldable structure design comes from tape-spring hinges, made from short lengths of steel tape measure, which have been used successfully many times as deployment mechanisms for spacecraft and other applications [1][2]. It is envisaged that integral CFRP tape-spring hinges will provide a lightweight, reliable, low-cost deployment mechanism for deployable booms, solar arrays, etc. to be used on the next generation of small satellites.

The elastic folding of tape springs made of isotropic material is well understood [3][4][5], the key features being that they form a folded region that is approximately straight transversally and uniformly curved longitudinally, with a radius of curvature equal to the radius of the cross-section of the undeformed tape-spring. Also, and remarkably, the curvature of the folded region is the same for "equal sense" and "opposite sense" folding, i.e. for both longitudinal curvatures in the same sense and opposite sense, respectively, to the original transverse curvature. The strain and hence stress distribution in the fold region can be straightforwardly determined from the elastic curvature changes, and it can be shown that the radius of transverse curvature to thickness ratio, $R / t$, of a tape spring has to be greater than $E /\left[\sigma_{y}(1-\nu)\right]$ to avoid yielding of the material (here $E$ is the Young's Modulus, $\sigma_{y}$ the yield stress, and $\nu$ the Poisson's ratio of the material).

Extending these results to anisotropic materials is straightforward [6] [7], but it is then found that tape springs made from woven prepregs are able to survive larger surface bending strains than the ultimate failure strains that are measured from standard coupon tests in tension and compression.

Effects of this type have been observed before. Wisnom [8] carried out bending tests on 26-ply unidirectional XAS/913, $3.35 \mathrm{~mm}$ thick specimens, and the observed strains were up to $2.5 \%$ on the compression surfaces. In pure compression, the maximum strain observed for this material was typically around $1 \%$. More recently, the existence of specimen size effects has been identified, see the extensive review in [9], whereby the maximum compressive strain at failure decreases when the dimensions of the specimen are increased. However, all previous work has been on relatively thick specimens; there is no previous work on the bending of very thin composites, which are essential for the design of structures that are able to fold elastically to a small radius. Furthermore, there

\footnotetext{
${ }^{1}$ Corresponding author: pellegrino@eng.cam.ac.uk
} 
is only limited published data on laminates made from woven fabrics [10], which are of specific interest for the present paper.

One-ply and two-ply laminates made from carbon fibre fabric (plain weave) with bi-directional fibres are investigated. The aim of this paper is to characterise and compare the maximum strains before failure in tension, compression and bending by means of simple coupon tests. Measuring the actual compressive strength of a laminate is very challenging. The procedure adopted here is based on a sandwich column layout [11] and the average measured strength is found to correlate well with predictions based on measurements of fibre waviness from micrographs of the laminates. The maximum strains in the fibre direction are $0.9 \%$ to $1.0 \%$ in tension, $0.4 \%$ to $1.0 \%$ in compression, and $1.9 \%$ to $2.8 \%$ in bending.

The paper is presented in five sections. Following this Introduction and Background, the section entitled Experimental Method describes the materials used in this study and then briefly illustrates the experimental methods used for the investigation. The following section presents the experimental results obtained, and is followed by the estimation of the compressive strength and maximum strain in compression of one-ply specimens. A discussion concludes the paper.

\section{EXPERIMENTAL METHOD}

All specimens were made from prepregs supplied by Hexcel, based on the low curing temperature 913 epoxy resin (prepreg 913C-814-40\%) and the 914 toughened epoxy resin (prepreg 914C-81440\%). These prepregs use the same plain weave T300 carbon fabric (3K fibres per tow) and have a 40\% resin content by weight; the dry fabric and the prepreg weigh 193 gsm and 322 gsm, respectively. During curing, the 913 prepregs were sandwiched between two steel plates, which resulted in a smooth finish on both sides. The 914 prepregs were cured directly in contact with the bleeder on one side, resulting in a rough surface finish. The thicknesses of the smooth specimens are $0.22 \mathrm{~mm}$ (one ply) and $0.43 \mathrm{~mm}$ (two plies), and are very uniform. The thickness of the rough specimens is much more variable, see Figure 8, and average values of $0.23 \mathrm{~mm}$ (one ply) and $0.46 \mathrm{~mm}$ (two plies) were obtained from several measurements with a micrometer. Each type of laminate was made as a single plate, from which individual specimens were cut with a circular diamond saw.

All tests were conducted using an Instron 4483 materials testing machine with a load cell of $150 \mathrm{kN}$. Longitudinal strain measurements were made with an LE-05 Electronic Instrument Research Ltd laser extensometer, using two strips of retro-reflective material centred in the middle of the specimen, at a distance of $50 \mathrm{~mm}$ in the tension and shear tests, and $25 \mathrm{~mm}$ in the compression tests.

\section{Tension Tests}

The specimens for the tensions tests were cut with the fibres aligned with and perpendicular to the direction of loading. The one-ply specimens are denoted by $[0,90]$ and the two-ply specimens by $[0,90]_{2}$. Following Method 302 in Ref. [12], for the measurement of the tensile strength and elastic modulus of multidirectional CFRP, $20 \mathrm{~mm}$ wide by $200 \mathrm{~mm}$ long parallel edge, unnotched specimens were sandwiched between $50 \mathrm{~mm}$ long aluminium end tabs with epoxy resin (trade name: Araldite Precision). In accordance with Ref. [13], the tests were carried out at a strain rate of $0.2^{-3} \mathrm{~s}^{-1}$. To achieve a more uniform distribution of stress in the fibres, each specimen was subjected to four load cycles up to about $80 \%$ of the ultimate stress, before being loaded up to failure. 


\section{In-plane Shear Tests}

The in-plane shear modulus and shear strength were measured by carrying out tension tests [14], on one-ply $[ \pm 45]$ and two-ply $[ \pm 45]_{2}$ specimens. These properties are required to predict the compressive strength.

\section{Compression Tests}

The compression tests were carried out on short sandwich columns, consisting of two CFRP face sheets bonded to a closed-cell PVC foam core, as shown in Figure 2. Fleck and Sridhar [11] have shown that by suitable choice of the properties of the foam the lateral restraint provided by the core can be optimised to prevent failure by overall Euler buckling, core shear macrobuckling, and face wrinkling so that the specimen fails by fibre microbuckling, which is closest to the expected mode of failure on the compression side of an ultra-thin laminate subjected to high bending strains.

Hence, the specimens were designed so that they would fail by fibre microbuckling. Having chosen a specimen width of $10 \mathrm{~mm}$ and length of $40 \mathrm{~mm}$, and a closed-cell PVC foam for the sandwich core (trade name: Divinvycell, density $186 \mathrm{~kg} / \mathrm{m}^{3}$ ), a core depth of $30 \mathrm{~mm}$ was required. The face sheets were bonded to the sandwich core using Araldite Precision epoxy resin, and were cured at room temperature.

Two changes were made to the procedure in Ref. [11]. First, our specimens were significantly narrower, due to the limited availability of material. Second, steel end plates were bonded to both ends of each specimen, to minimize any stress concentrations.

\section{Bending Tests}

The aim of the bending test is to determine the smallest radius of curvature that a particular specimen will survive without failing. Because of their thinness, one- and two-ply laminates can be folded to very small radii; hence the standard three-point and four-point bending test layouts are unsuitable. An alternative layout has been devised, as shown in Figure 3, which permits very large displacements and applies a relatively uniform bending moment and hence curvature over the centre region of a specimen that is near to failing in bending.

Specimens with a width of $15 \mathrm{~mm}$ were cut to a length of $\pi R_{\min }+30 \mathrm{~mm}$, where $R_{\min }$ is the estimated minimum radius of curvature, were attached with $3 \mathrm{M} 79$ glass tape to square rods connected to the Instron end fixings. Then, the cross-head of the Instron was driven at a rate of $0.1 \mathrm{~mm} / \mathrm{s}$, and a Sony DCR-PC110E digital video camera was used to take images of the specimen under different amounts of end shortening. Once the specimen had failed, the last few images from the movie were used to measure the radius of curvature of the specimen before failure.

Note that if the specimen is too long the rods to which it is attached will come into contact before the specimen fails. When this happens, the test has to be repeated with a shorter specimen.

\section{EXPERIMENTAL RESULTS}

A sample plot of the measurements taken from each of the four tests described above are presented in this section.

Figure 4 shows the stress-strain response of a particular T300/913 [0,90] specimen; note that the response is clearly linear elastic until failure, at a longitudinal strain $\epsilon \approx 1.14 \%$. The average elastic modulus parallel to the fibre direction was found to be $60 \mathrm{GPa}$ for the T300/913 samples and 52 Gpa for the T300/914 samples, for both one ply and two ply laminates. Using the material properties 
in Table 1, rule of mixtures estimates of $60 \mathrm{GPa}$ and $56 \mathrm{GPa}$ are obtained for the T300/913 (fibre volume fraction 50\%) and T300/914 (fibre volume fraction 47\%) laminates, respectively.

Figure 5 shows the behaviour in shear, which characterizes the non-linear behaviour of the matrix. The average shear moduli from the experiments were 3.0 GPa and 3.1 GPa respectively for T300/913 and T300/914 specimens.

Figure 6 shows a plot of compressive stress versus strain for one of the very few compression tests in which the specimen failed by fibre micro-buckling; delamination and Euler buckling due to separation from the foam core were more common failure modes. The full compressive strength of a specimen was difficult to achieve and the measured values of the compressive modulus were also rather variable, although generally higher than the tension modulus.

Figure 7 is a plot of the axial load versus end displacement from the bending test. This plot is not required for the calculation of the maximum bending strain (which is obtained from the digital images taken during the tests) but is an interesting example of the post-buckled response of an Euler strut that comes into contact with end attachments and thus becomes stiffer. It can be used to estimate the flexural modulus of the specimen. The maximum bending strain occurs on the outermost surface of the specimen and, given the thickness $t$ of the specimen and the smallest radius of curvature observed in the bending test

$$
\varepsilon_{l}=\frac{t}{2 R_{\min }}
$$

The maximum strains derived from the tension, compression and bending tests are summarised in Table 2. Overall, the average maximum strain in tension, in the direction of the fibres, is around $1.0 \%$ when the fibres are aligned with the directions of principal strain. The average maximum strain in compression is around $0.7 \%$, for all specimens. The maximum bending strain in the direction of the fibres is typically $2.7 \%$ for one ply and $2.1 \%$ for two plies, when the fibres are along the directions of principal strain. When the fibres are at $45^{\circ}$ to the directions of principal strain, which is the case when a bending test is is carried out on a [ \pm 45$]$ specimen, the maximum average fibre strain is around $2.5 \%$ for one ply and $1.8 \%$ for two plies.

Table 3 shows that the tensile strengths of T300/913 and T300/914 one-ply and two-ply laminates are similar, with average values of approximately $548 \mathrm{MPa}$ and $469 \mathrm{MPa}$ respectively. The compressive strength for one ply, though, is higher than that for two plies, and viceversa in terms of shear strength. Finally, it can be noted that overall the T300/913 specimens have performed better than T300/914.

\section{ESTIMATION OF COMPRESSIVE STRENGTH}

The measured compressive strength of one-ply specimens was predicted from the measured shear modulus. According to Ref. [15], the dominant mechanism of compressive failure in polymermatrix composites is plastic microbuckling. Hence, the compressive strength is controlled by fibre misalignment together with plastic shear deformation of the matrix. Their compressive strength can be estimated from

$$
\sigma_{C}=\frac{\tau_{y}}{\gamma_{y}+\bar{\phi}}=\frac{G}{1+\bar{\phi} / \gamma_{y}}
$$

where $\tau_{y}$ is the yield strength of the composite in shear, $\gamma_{y}$ is the corresponding yield strain $\left(\gamma_{y}=\tau_{y} / G\right)$, and $\bar{\phi}$ is the maximum initial misalignment angle of the fibres.

Figure 8 shows a micrograph of a one-ply specimen from which an initial fibre misalignment angle of 0.091 rad was measured. By substituting this value into Equation 2, together with the shear modulus from the section In-Plane Shear Tests and the shear strength from Table 3, a compressive strength of around $428 \mathrm{MPa}$ was estimated. This value correlates well with the average measured 
values of around $357 \mathrm{MPa}$ and, considering the large scatter in the measured strength, this indicates that the full compressive strength has been captured reasonably well in the tests.

\section{DISCUSSION AND CONCLUSION}

The behaviour of one-ply (respectively 0.22 and $0.23 \mathrm{~mm}$ thick) and two-ply (respectively 0.43 and $0.46 \mathrm{~mm}$ thick) woven T300/913 and T300/914 specimens can be described as follows.

In tension (along one set of fibres) they are linear up to failure, which occurs at an average strain of $1.0 \%$. This behaviour is quite repeatable, the standard deviation in the maximum strain being around $9 \%$. In compression (also along one set of fibres) they often show a non-linear response, due to bedding-in deformation, end brooming, and delamination. The measurements of maximum compressive strain were much less repeatable, the overall average being $0.7 \%$. In in-plane shear (at $45^{\circ}$ to the fibres) their response is matrix dominated and hence also non-linear.

The most useful test, from the viewpoint of the application of thin composites to deployable structures, is their bending behaviour, which has been characterised by means of a largedisplacement buckling test. The maximum surface strains in the direction of the fibres are around $2.8 \%$ for one-ply and $1.9 \%$ for two-ply specimens. These values were obtained for bending the specimens with the principal strain directions parallel to the fibres. Somewhat smaller maximum fibre strains, by up to $15 \%$, were obtained for the fibres and the principal strain directions at $45^{\circ}$. It should be noted that - because in the latter case the major principal strain, which controls the maximum bending curvature that can be applied to a specimen, is twice the value along the fibres - all $[ \pm 45]$ specimens can be folded to a much tighter radius than $[0,90]$ specimens of equal thickness. Finally, it should be noted that the proposed bending test is straightforward to carry out and the measurements are very repeatable.

A comparison of one-ply and two-ply laminates, in Table 2 , shows that the ultimate strains along the fibres - measured from bending tests - are on average $36 \%$ higher in one-ply laminates. Generally, the maximum surface strains that have been measured in the present study are much larger than the failure strains of T300 fibres (for which Toray quote a failure strain of 1.6\%).

Scaling effects could be invoked to justify these results. For example, a recent computational study, see Section 5 of Ref. [16], has shown that scaling effects rapidly increase when the ratio between specimen thickness and fibre diameter is less than 200; in the present study this ratio is in the range 40-80. However, we believe that in the present case high surface strains do not correspond to equally high peak strains in the fibres. Figure 8 shows the cross section of a thin specimen made from a single-ply woven fabric; note that it consists of thin and wide bundles of fibres whose thickness is, in this case, approximately half the total thickness of the specimen. If, instead of assuming that the specimen behaves as an orthotropic plate, we assume a threedimensional grillage of beams - where each bundle of fibres forms a beam - then each beam will have to bend about its own neutral axis and so the maximum strain will be half the strain obtained from the plate model. A more detailed study along these lines is currently being completed.

Regarding the design of tightly folded regions in deployable composite structures, it can be concluded that this should be based on allowable bending strains that are either measured directly from coupon bending tests or - for preliminary design - on the values presented in this paper. Finally, with reference to the design of CFRP tape springs discussed in the Introduction, the reader should be aware that the results presented in this paper apply to folding in one direction only, whereas a tape spring undergoes biaxial changes of curvature. The interaction between strains on two set of orthogonal fibres will need to be considered. 


\section{ACKNOWLEDGEMENTS}

The authors are grateful to Mr G. Dando and Dr M.F. Sutcliffe for help and advice during the course of this study, and wish to thank Mr J. Ellis of Hexcel, Duxford, UK for providing materials and manufacturing facilities. Helpful comments by an anonymous reviewer are acknowledged. Financial support from Corpus Christi College and QinetiQ Ltd is gratefully acknowledged.

\section{References}

[1] Chironis NP, Sclater N. Mechanisms and mechanical devices sourcebook. Second Edition, McGraw-Hill, New York, 1996.

[2] Vyvyan WW. Self-actuating, self-locking hinge. U.S. Patent 3,386,128. June 4th 1968.

[3] Rimrott FPJ. "Storable tubular extendible member: a unique machine element". Machine Design, 1965;37:156-163.

[4] Calladine CR. "Love Centenary Lecture: The theory of thin shell structures 1888 - 1988". The Institution of Mechanical Engineers Proceedings, 1988;202(42):1-9.

[5] Seffen KA, Pellegrino S. "Deployment dynamics of tape springs". Proceedings of the Royal Society of London, Part A, 1999;455:1003-1048.

[6] Iqbal K. Mechanics of laminated bi-stable tubular structures. PhD Dissertation, Department of Engineering, University of Cambridge, 2001.

[7] Yee JCH. "A study of the principles for foldable composite structures". First-Year Report, Department of Engineering, University of Cambridge, 2002.

[8] Wisnom MR. "On the high compressive strains achieved in bending tests on unidirectional carbon-fibre/epoxy". Composites Science and Technology, 1992;43:1992.

[9] Wisnom MR. "Size effects in the testing of fibre-composite materials", Composites Science and Technology, 1999;59:1937-1957.

[10] Hou JP, Ruiz C. "Measurement of the properties of woven CFRP T300/914 at different strain rates". Composites Science and Technology, 2000;60:2829-2834.

[11] Fleck NA, Sridhar I. "End compression of sandwich columns". Composites: Part A - Applied Science and Manufacturing, 2002;33:353-359.

[12] Curtis PT. CRAG test methods for the measurement of the engineering properties of fibre rinforced composites. Royal Aerospace Establishment, Farnborough Report Technical Report $88012,1988$.

[13] American Society for Testing and Materials. "Standard Test Method for Tensile Properties for Fiber-Resin Composites". Standards and Literature References for Composite Materials, Second Edition, 1990.

[14] D3518/D3518M-94, A. "Standard test method for in-plane shear response of polymer matrix composite". American Society For Testing and Materials, 2000.

[15] Budiansky B, Fleck NA. "Compressive failure of fibre composites". Journal of Mechanics and Physics of Solids, 1993;41:183-221.

[16] Fleck NA, Liu D. "Microbuckle initiation from a patch of large amplitude fibre waviness in a composite under compression and bending". European Journal of Mechanics A/Solids, 2001; 20:23-37. 
Table 1: Properties of fibres and resins

\begin{tabular}{lccc}
\hline \hline & T300 & 913 & 914 \\
\hline \hline Young's Modulus, $E(\mathrm{GPa})$ & 230 & 3.39 & 3.9 \\
Shear Modulus, $G(\mathrm{GPa})$ & 8.96 & 1.21 & 1.4 \\
Poisson's ratio, $\nu$ & 0.2 & 0.41 & 0.41 \\
Density, $\rho\left(\mathrm{kg} / \mathrm{m}^{3}\right)$ & 1770 & 1230 & 1290 \\
Tensile Strength, $\sigma_{T S}(\mathrm{MPa})$ & 3200 & 65.5 & 47.7 \\
Compressive Strength, $\sigma_{C S}(\mathrm{MPa})$ & 2000 & - & 180 \\
\hline \hline
\end{tabular}

Table 2: Ultimate strains along fibres

\begin{tabular}{clccc}
\hline \hline Specimen & Orientation & $\begin{array}{c}\text { Tension } \\
\varepsilon_{T}(\%)\end{array}$ & $\begin{array}{c}\text { Compression } \\
\varepsilon_{C}(\%)\end{array}$ & $\begin{array}{c}\text { Bending } \\
\varepsilon_{B}(\%)\end{array}$ \\
\hline \hline T300/913 & {$[0,90]$} & $1.00 \pm 0.09$ & $0.95 \pm 0.12$ & $2.71 \pm 0.05$ \\
& {$[ \pm 45]$} & - & - & $2.29 \pm 0.02$ \\
& {$[0,90]_{2}$} & $0.99 \pm 0.04$ & $0.69 \pm 0.01$ & $1.89 \pm 0.09$ \\
& {$[ \pm 45]_{2}$} & - & - & $1.77 \pm 0.03$ \\
T300/914 & & & & \\
& {$[0,90]$} & $0.96 \pm 0.11$ & $0.37 \pm 0.03$ & $2.77 \pm 0.02$ \\
& {$[ \pm 45]$} & - & - & $2.64 \pm 0.03$ \\
& {$[0,90]_{2}$} & $0.92 \pm 0.13$ & $0.62 \pm 0.14$ & $2.19 \pm 0.11$ \\
& {$[ \pm 45]_{2}$} & - & - & $1.78 \pm 0.04$ \\
\hline \hline
\end{tabular}

Table 3: Strength of laminates

\begin{tabular}{lccc}
\hline \hline Specimen & $\begin{array}{c}\sigma_{T} \\
\text { Tension } \\
(\mathrm{MPa})\end{array}$ & $\begin{array}{c}\sigma_{C} \\
\text { Compression } \\
(\mathrm{MPa})\end{array}$ & $\begin{array}{c}\tau \\
\text { Shear } \\
(\mathrm{MPa})\end{array}$ \\
\hline \hline T300/913, one-ply & $582.0 \pm 58.8$ & $523.9 \pm 92.3$ & $67.9 \pm 1.5$ \\
T300/913, 2-ply & $513.7 \pm 2.4$ & $484.4 \pm 24.1$ & $93.2 \pm 9.5$ \\
& & & \\
T300/914, one-ply & $486.3 \pm 40.6$ & $356.8 \pm 25.5$ & $50.6 \pm 5.6$ \\
T300/914, 2-ply & $451.9 \pm 24.4$ & $326.6 \pm 25.4$ & $75.0 \pm 7.1$ \\
\hline \hline
\end{tabular}




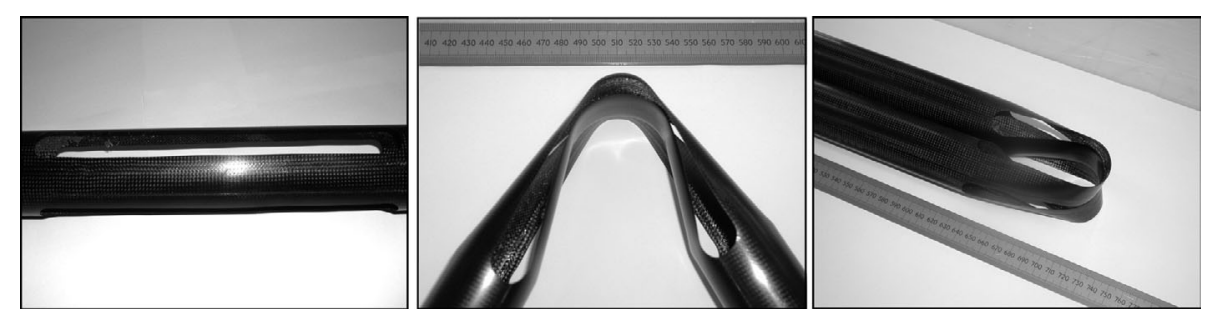

Figure 1: Deployable CFRP boom hinge (unfolded, folded $110^{\circ}$, folded $180^{\circ}$ ).

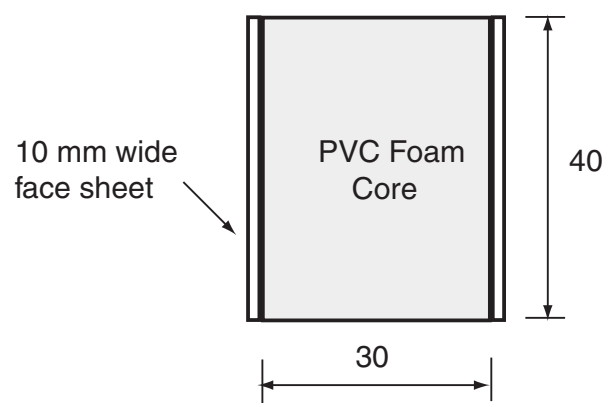

Figure 2: Sandwich column compression specimen (dimensions in $\mathrm{mm}$ ).

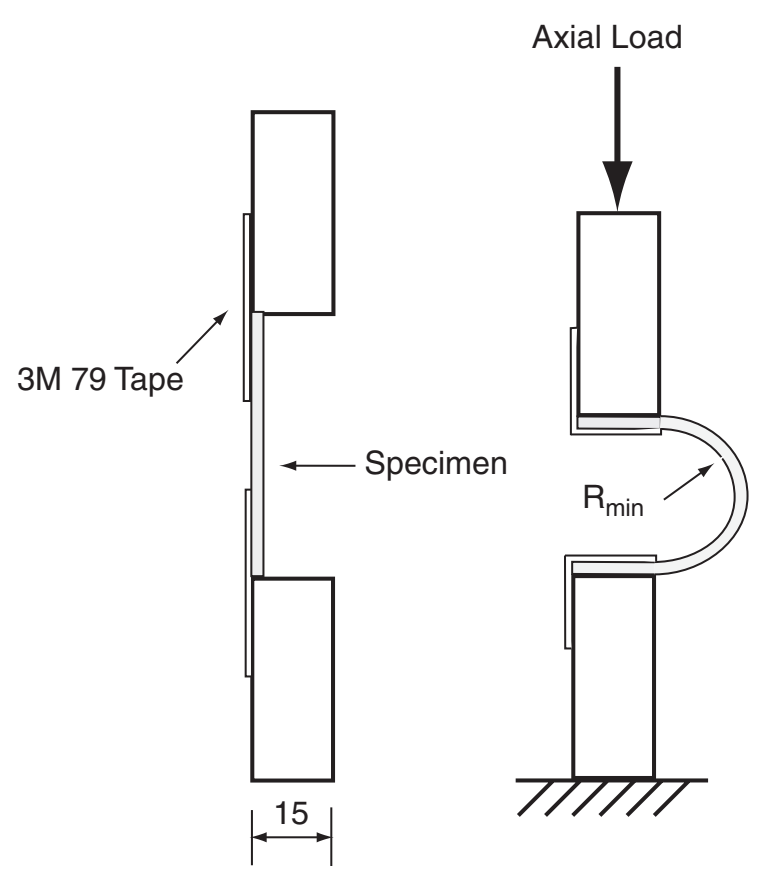

Figure 3: Layout of bending test (dimensions in $\mathrm{mm}$ ). 


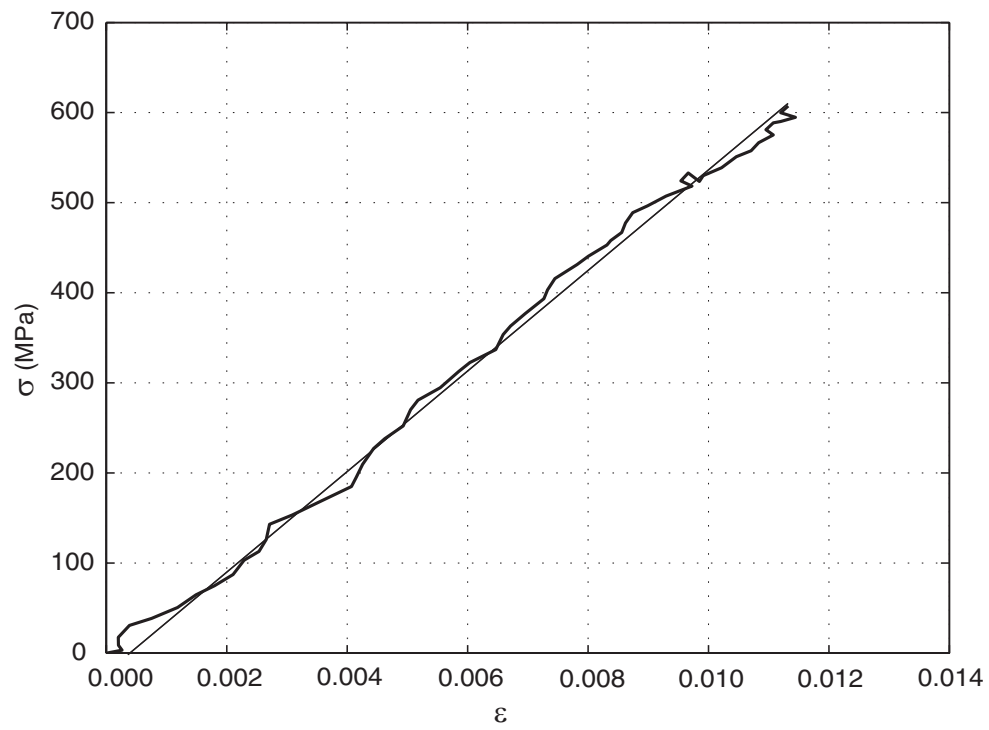

Figure 4: Stress-strain response from tension test on one-ply T300/913.

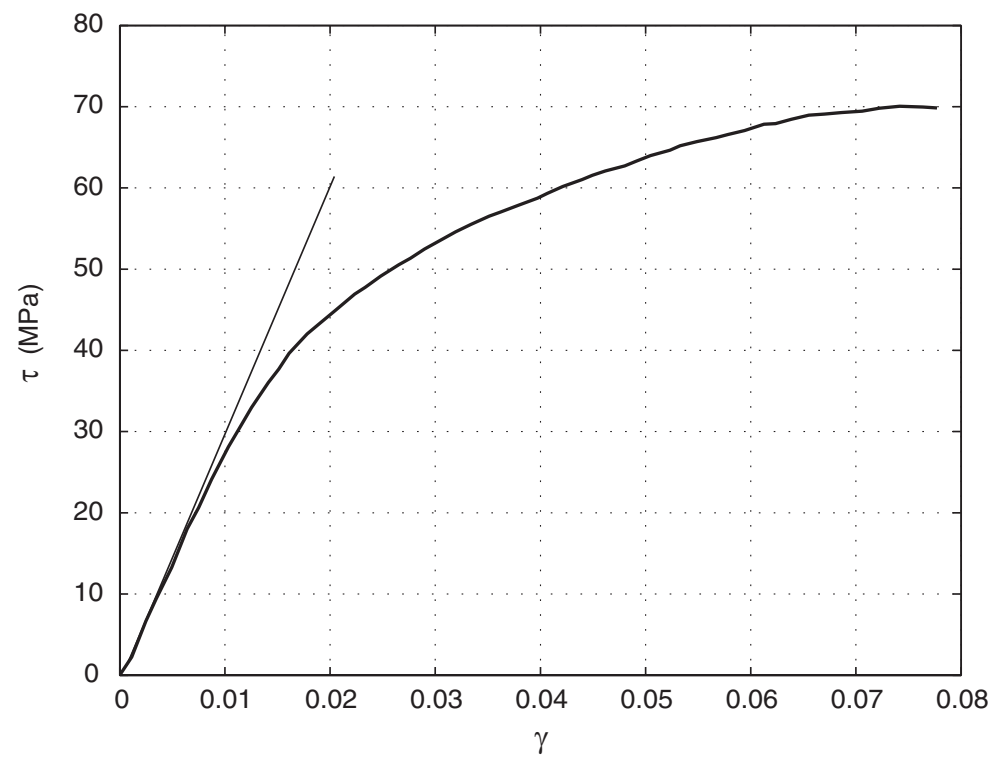

Figure 5: Stress-strain response from in-plane shear test on one-ply T300/913. 


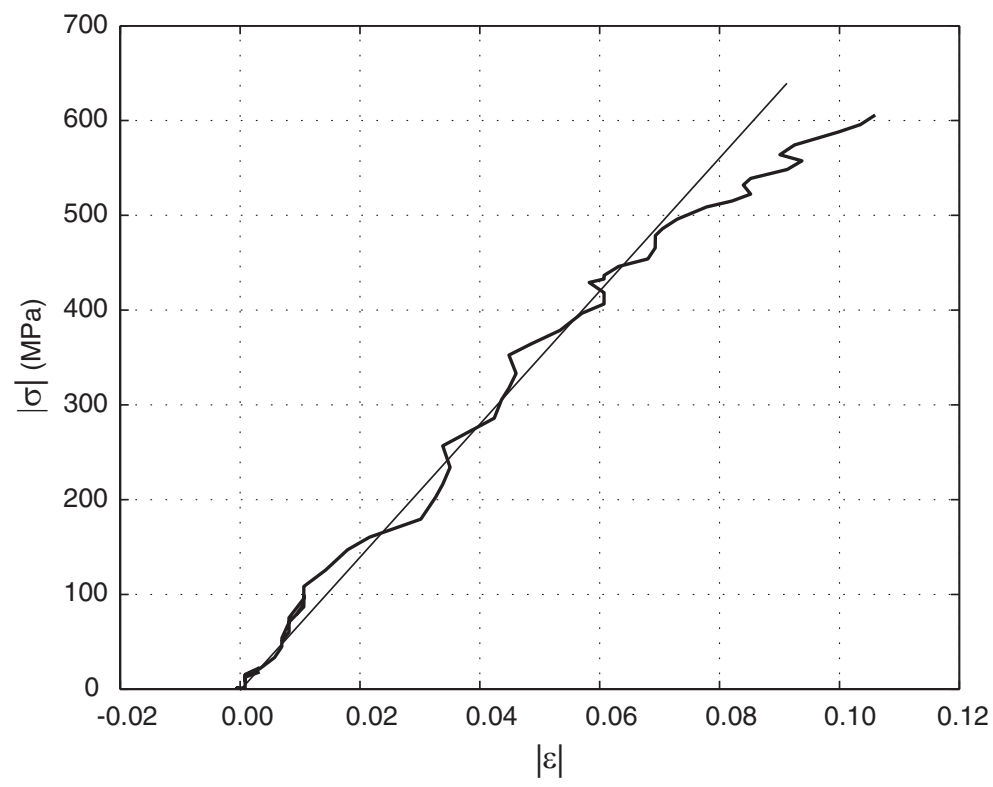

Figure 6: Stress-strain response from compression test on one-ply T300/913.

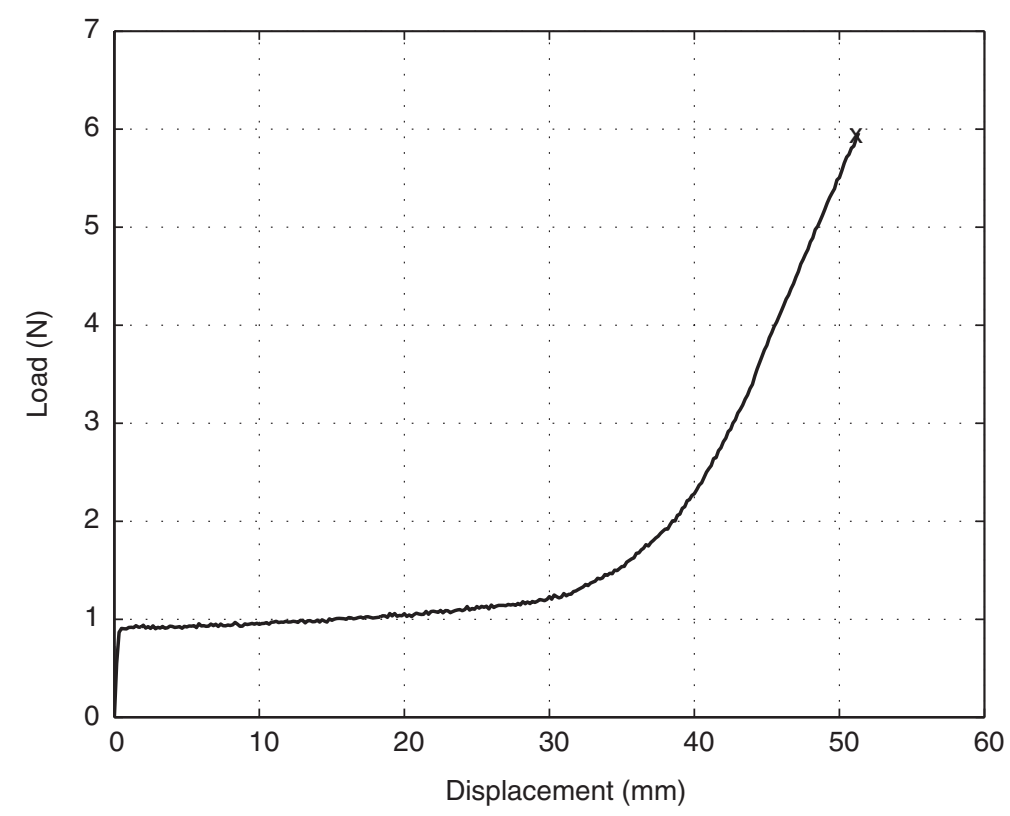

Figure 7: Load-displacement measurements from bending test on one-ply T300/913.

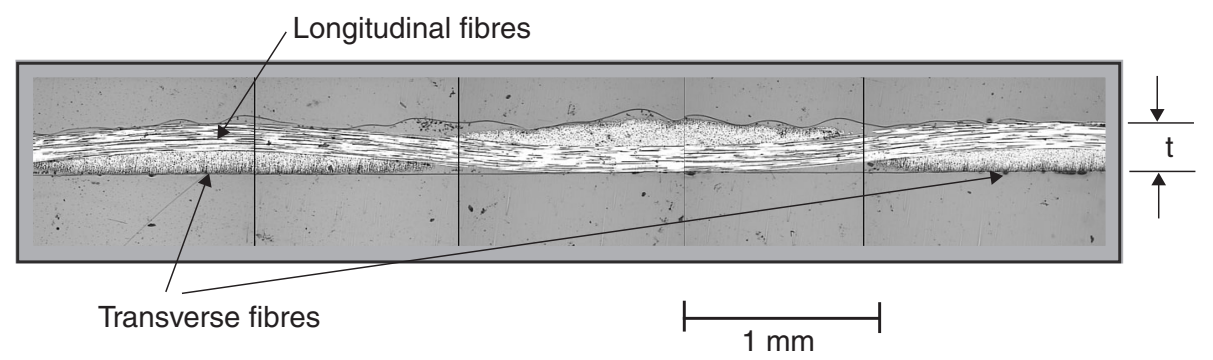

Figure 8: Optical microscope image of microstructure of one-ply T300/914. 